\title{
Photo-Induced Proton Transfers of Microbial Rhodopsins
}

\author{
Takashi Kikukawa', Jun Tamogami², Kazumi Shimono², \\ Makoto Demura1, Toshifumi Nara² and Naoki Kamo² \\ ${ }^{1}$ Faculty of Advanced Life Science, Hokkaido University, \\ ${ }^{2}$ College of Pharmaceutical Sciences, Matsuyama University, \\ Japan
}

\section{Introduction}

Microbial rhodopsins are photoactive membrane proteins that are widely distributed over the microbial world. They commonly consist of seven transmembrane helices forming an internal pocket for a chromophore retinal, whose photo-induced isomerization triggers the respective photochemical reactions of these proteins. They are generally classified into photosensors or ion-pumps, but the members of both classes have individualities. In the case of photosensors, there exist a variety of signal-transduction modes, including interaction with other membrane proteins, interaction with cytoplasmic proteins, and lightgated ion channel activity. For ion-pumps, there exist outwardly directed $\mathrm{H}^{+}$pumps and inwardly directed $\mathrm{Cl}^{-}$pumps. In spite of these functional diversities, most microbial rhodopsins show photo-induced proton-transfer reactions among amino acid residues and the external medium. These reactions reflect the $\mathrm{pKa}$ changes of some residues induced by the protein conformational changes during the respective photochemical reactions. To analyze these reactions, it is indispensable to detect the small $\mathrm{pH}$ changes of the external medium due to the proton release/uptake during the photoreaction cycles. Electrochemical cells using indium-tin oxide (ITO) or tin oxide $\left(\mathrm{SnO}_{2}\right)$ transparent electrodes are a powerful and convenient tool that enables such measurement in external media under a variety of $\mathrm{pH}$ conditions (Robertson \& Lukashev, 1995; Wang et al., 1997; Koyama et al., 1998a; Tamogami et al., 2009; Wu et al., 2009). Here, we will describe the rapidly expanding family of the microbial rhodopsins and the application of the ITO method to their photoresponses.

\section{Visual rhodopsins and archaeal rhodopsins}

Rhodopsin is a protein in the retina of animals that works as a light sensor. Rhodopsin contains retinal (vitamin A aldehyde) as a chromophore and its absorption maximum is $\sim 500 \mathrm{~nm}$. Retinal binds with a specific lysine residue via a protonated Schiff base. Absorption of photons induces the isomerization of 11-cis to all-trans retinal and subsequent conformational changes including the deprotonation of the Schiff base (J.L. Spudich et al., 2000). Rhodopsin had been considered to be confined to animals until the findings from haloarchaea. 
In the early 1970s, however, a retinal protein was discovered in the membrane of the highly halophilic archaeon Halobacterium salinarum (formally halobium). The natural habitats of $H$. salinarum are the Dead Sea, the Great Salt Lake and salt ponds. The newly discovered rhodopsin was named bacteriorhodopsin (BR), and it was shown to act as a light-driven proton pump (Oesterhelt \& Stoeckenius, 1971). By using light energy, BR transports a proton from a cytoplasmic to an extracellular space, which produces the protonelectrochemical potential difference across the membranes, which in turn drives the synthesis of ATP via $\mathrm{H}^{+}$-ATPase. Light irradiation to BR induces the retinal isomerization from all-trans to 13-cis, while the isomerization of visual rhodopsins is from 11-cis to alltrans. In addition, the most significant difference from the visual rhodopsins is the existence of a so-called photocycle: light absorption leads to the excitation of the pigment, which decays to the original pigment via a variety of photo-intermediates. This linear cyclic photochemistry is called a photocycle. On the other hand, for most visual rhodopsins, the Schiff base linkage with the retinal is disrupted as a consequence of the photochemical reaction. The proton-transfer mechanism of BR has been intensively investigated so far. During the photocycle, the protonated Schiff base affords its proton to the extracellular space and receives another proton from the other side, i.e., the cytoplasmic space. Thus, this cycle involves the alternation between the protonated and deprotonated states of the Schiff base.

Later, three additional retinal proteins were discovered in $H$. salinarum. These were halorhodopsin (HR) (Matsuno-Yagi \& Mukohata, 1977; Schobert \& Lanyi, 1982; Mukohata et al., 1999; Váró et al., 2000; Essen, 2002), sensory rhodopsin I (SRI) (Bogomolni \& J.L Spudich, 1982; Hazemoto et al., 1983; J.L Spudich \& Bogomolni, 1984) and sensory rhodopsin II (SRII, also called phoborhodopsin) (Takahashi et al., 1985; Tomioka et al., 1986; Wolff et al., 1986; E.N. Spudich et al., 1986; Marwan \& Oesterhelt, 1987). BR and HR are light-driven ion pumps: $\mathrm{HR}$ is an inwardly directed $\mathrm{Cl}^{-}$-pump and $\mathrm{BR}$ is an outwardly directed $\mathrm{H}^{+}$-pump as described above. On the other hand, SRI and SRII act as receptors of phototaxis. In the cell membranes, these receptors form firm complexes with their cognate transducers. By utilization of these sensing systems, the cell moves toward light of the preferred wavelength $(\lambda>520 \mathrm{~nm})$ where BR and HR can work, and escapes from the shorter wavelength light $(\lambda<520 \mathrm{~nm})$ which may contain dangerous UV light. These retinal proteins also exhibit their own functions during the respective photocycles. Under the physiological states, HR and two SRs do not exhibit the proton-pumping activities. However, the photocycles of two SRs involve alterations between the protonated and deprotonated states of the Schiff bases, resulting in the proton releases and uptakes at the extracellular sides (Bogomolni et al., 1994; Sasaki \& J.L. Spudich, 1999, 2000).

\section{Microbial rhodopsins}

About 30 years after the discovery of BR, archaeal rhodopsin homologues began to be identified in various microorganisms, including proteobacteria, cyanobacteria, fungi, dinoflagellates, and alga (J.L. Spudich \& Jung, 2005). Thus, the microbial species containing the retinal protein genes inhabit a broad range of environments. At present, these rhodopsin homologues are called type 1 rhodopsins or microbial rhodopsins, and they define a large phylogenetic class spreading to all three domains of life, i.e., archaea, bacteria and eukarya. 
To distinguish them from rhodopsins in the microbial world, the rhodopsins in animals are called type 2 rhodopsins.

Studies on BR, HR, SRI and SRII have shown that two amino acid residues corresponding to Asp85 and Asp96 in BR are key residues for the functional difference among these archaeal rhodopsins. As mentioned above, the Schiff bases of BR and two SRs become deprotonated during the early halves of the photocycles. Asp85BR and the corresponding aspartates of SRs function as the proton acceptors from the Schiff bases. For HR, on the other hand, Asp85BR is replaced by Thr, and thus $\mathrm{HR}$ can bind $\mathrm{Cl}^{-}$, a transportable ion, to the vicinity of the Thr and the protonated Schiff base. The other residue, Asp96BR, functions as a proton donor for the reprotonation process of the Schiff base and contributes to acceleration of the turnover rate of the photocycle. This residue is not conserved in the two SRs and consequently their photocycles are much slower than that of BR. HR also undergoes a fast photocycle in the manner of BR but does not conserve this aspartate, because HR undergoes its photocycle without the deprotonation of the Schiff base.

On the basis of these findings, the physiological functions of newly found microbial rhodopsins have been deduced from the conservation states of the residues corresponding to Asp85 $\mathrm{BR}$ and Asp96 $\mathrm{BR}$. In addition to these clues, the functions of some proteins have been confirmed experimentally by using the purified proteins and/or by observation of their photo-induced behaviors. From these analyses, the newly found microbial rhodopsins are now categorized as either ion-pumps $\left(\mathrm{H}^{+}\right.$or $\left.\mathrm{Cl}^{-}\right)$or photoreceptors. In paticular, many newly found pigments are categorized as $\mathrm{H}^{+}$pumps. This fact suggests that the utilization of light energy via $\mathrm{H}^{+}$pumps is widely adopted in the microbial world. For many $\mathrm{H}^{+}$pumps, the pumping activities have been experimentally confirmed. Representative examples include proteorhodopsin (PR) from proteobacteria living throughout the world's oceans (Béjà et al., 2000); xanthorhodopsin (XR) from Salinibacter ruber, a highly halophilic eubacterium (Balashov et al., 2005); Leptosphaeria rhodopsin (LR) from Leptosphaeria maculans, a fungal pathogen to a plant (Waschuk et al., 2005); Gloeobacter rhodopsin (GR) from Gloeobacter violaceus, a cyanobacterium living in fresh water (Miranda et al., 2009); and Acetabularia rhodopsin (AR) from a gigantic unicellular marine algae, Acetabularia acetabulum, which reaches to $10 \mathrm{~cm}$ in height (Tsunoda et al., 2006). Recently, two clones of AR, named ARI and ARII, were isolated from the same organism (Lee et al., 2010). These were somewhat different from the original AR. For ARII, the $\mathrm{H}^{+}$-pumping activity was confirmed using Xenopus oocytes and the detailed photochemistry was examined with the help of a cell-free expression system (Wada et al., 2011; Kikukawa et al., 2011). On the other hand, photosensing rhodopsins have also been found in bacteria and eukarya. Although these represent only a minority of the newly found microbial rhodopsins, they exhibit a variety of signal-transduction mechanisms. Two SRs in the archaeal membrane relay the photosignals to the cognate transducer proteins embedded in the membrane. From the eubacterium S. ruber, SRI itself was found and has been extensively characterized (KitajimaIhara et al., 2008). Unlike these SRs, the photosensor called Anabaena sensory rhodopsin (ASR) from Anabaena sp. PCC7120, a cyanobacterium living in fresh water, is considered to relay the signal to the soluble protein (Jung et al., 2003). Anabaena does not have a flagellum and so does not show the phototaxis. Instead, Anabaena shows a photoresponse called chromatic adaptation. Thus, it is considered that ASR controls the biosynthesis of chromoproteins forming the light-harvesting complex. In addition to these, a new type of 
photosensing rhodopsin called channelrhodopsin was found in Chlamydomonas reinhardtii, a green flagellate alga (Sineshchekov et al., 2002; Nagel et al., 2002; Suzuki et al., 2003). This is a light-gated ion channel and induces the photomotile behavior of the cell. Thus, the world of microbial rhodopsins is now rapidly expanding.

\section{The photo-induced proton transfer associated with the photocycle of microbial rhodopsins}

Microbial rhodopsins have linear cyclic photochemical reactions called photocycles. For all microbial rhodopsins examined so far, the retinal Schiff bases are protonated in their dark states under physiological conditions. Except in the case of $\mathrm{HR}, \mathrm{a} \mathrm{Cl}^{-}$ion pump, the Schiff bases become deprotonated during the photocycles independent of $\mathrm{H}^{+}$-pumping or photosensing rhodopsins. As described below, these primary and the subsequent protontransfer reactions are closely related to the functions of both microbial rhodopsins.

\section{1 $\mathrm{H}^{+}$-pumping rhodopsins}

The illumination of the pigment protein leads to the excited state, which is relaxed thermally to the original pigment via various photochemical intermediates (Fig. 1A). The best-studied rhodopsin is BR (Haupts, 1999; Balashov, 2000; Heberle, 2000; Lanyi, 2004, 2006), and the $\mathrm{H}^{+}$-pumping mechanism of $\mathrm{BR}$ is described below. $\mathrm{BR}$ at the ground state and the intermediates $\mathrm{K}, \mathrm{L}, \mathrm{M}, \mathrm{N}$ and $\mathrm{O}$ have been investigated with various biophysical methods. The photocycle comprises stepwise reactions of the thermal reisomerization of the photoisomerized 13-cis retinal to the initial all-trans, and the proton is transferred toward the higher $\mathrm{pKa}$ residue accompanied with $\mathrm{pKa}$ changes during the photocycle. Reflecting the differences in protein conformation and protonation states of some residues, the intermediates assume the respective absorption spectra. The photoisomerization from initial all-trans to 13-cis retinal is completed until the formation of K-intermediate. The subsequent proton transfer observed at around neutral $\mathrm{pH}$ occurs as the following sequence (see Fig. $1 \mathrm{~A}$ and B). First, the deprotonation of the protonated Schiff base occurs in the formation of Mintermediate. The proton from the Schiff base is transferred to its counterion Asp85BR and the subsequent proton release to the extracellular (EC) space occurs from the protonreleasing complex (PRC) consisting of Glu194BR, Glu204 ${ }^{\mathrm{BR}}$, Arg82 ${ }^{\mathrm{BR}}$ and water molecules. Next, the proton of protonated Asp96 ${ }^{\mathrm{BR}}$ locating at the cytoplasmic (CP) channel transfers to the Schiff base in the M-N transition, which lead to the reprotonation of the Schiff base. Then the deprotonated Asp96 ${ }^{\mathrm{BR}}$ uptakes a proton from the CP space in the N-O transition, which is accompanied by the reisomerization of retinal to the initial all-trans state. Finally, the proton of protonated Asp85BR is transferred to PRC during the decay of O-intermediate, and then the protein returns to the original state. This series of proton-transfer reactions accomplishes the net proton transport from the CP to EC side.

As mentioned above, a light-driven proton pump has been found in many microorganisms belonging to bacteria and eukarya. These rhodopsins also undergo the photocycle including the intermediates similar to those of BR. However, there are several differences in the photocycles and proton transfers between $\mathrm{BR}$ and other $\mathrm{H}^{+}$-pumping rhodopsins. Examples are as follows. (1) PR from marine bacteria also goes through $\mathrm{K}, \mathrm{L}, \mathrm{M}, \mathrm{N}$ and $\mathrm{O}$ (or PR') intermediates at around neutral pH (Dioumaev et al., 2002; Friedrich et al., 2002; Váró et al., 
2003). However, the proton movement from the proton donor residue (Glu108PR corresponding to Asp96BR) to the Schiff base and its subsequent proton uptake from the $\mathrm{CP}$ space occur simultaneously in the M-N transition (Dioumaev et al., 2002). For BR, these two proton movements occur separately in the $\mathrm{M}-\mathrm{N}$ and $\mathrm{N}-\mathrm{O}$ transitions. (2) For ARII from marine algae, the photocycle includes much larger reverse reactions between $\mathrm{L}, \mathrm{M}, \mathrm{N}$ and $\mathrm{O}$ than are seen in BR (Kikukawa et al., 2011). Although the reverse reactions are also present in BR, their rates in ARII appear to be much larger than in BR. A rapid reverse reaction might be disadvantageous for the unidirectional ion pumping. (3) For all microbial rhodopsins, the proton conduction channel is bisected by retinal. For BR, these two channels are severely isolated and, in the dark state, the $\mathrm{CP}$ half channel is kept under a highly hydrophobic condition. This asymmetric structure had been believed to be important for the ion pumping function. For several proton pumps such as $\mathrm{XR}$ and GR, however, this characteristic structure of BR is not conserved (Luecke et al., 2008; Miranda et al., 2009). Therefore, the newly found proton pumps seem to adopt a mechanism that is at least partly different from that in BR. Thus, it would be an interesting subject to clarify the essential mechanisms for the respective proton pumps.
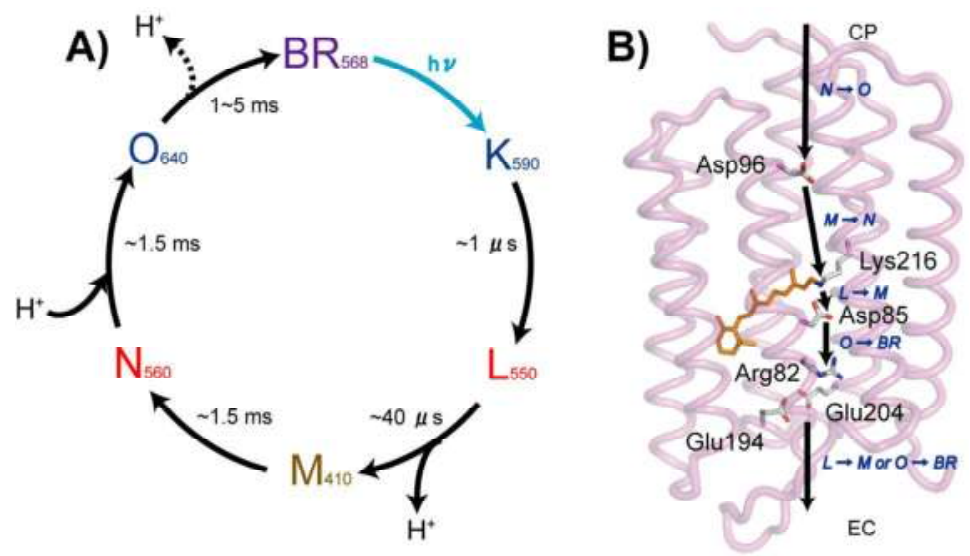

Fig. 1. The photocycle scheme (A) and the structure of BR (B) with the important residues involved in the proton-transfer reactions.

In (A), BR, K, L, M, N and O represent the unphotolyzed state and intermediates, respectively. Their $\lambda_{\max }$ 's are given in the subscripts, and the lifetimes of the intermediates are also shown. The photoisomerization of the retinal by illumination triggers the stepwise photoreactions accompanied with the proton movements. In (B), these proton transfers at respective steps are indicated with arrows (see section 4.1 for the details). The timing of proton transfer depends on the $\mathrm{pH}$ of the medium. Above $\mathrm{pH} 5$, the proton release occurs in L-decay while below at about $\mathrm{pH} \mathrm{5,} \mathrm{the} \mathrm{proton} \mathrm{release} \mathrm{occurs} \mathrm{in} \mathrm{O-decay} \mathrm{(arrow} \mathrm{with} \mathrm{a} \mathrm{broken} \mathrm{line)} \mathrm{instead} \mathrm{of} \mathrm{L-}$ decay. The structure in (B) was drawn from the PDB coordinate file 1C3W.

\subsection{Photosensing rhodopsins}

During the photocycles of almost all photosensing rhodopsins examined so far, the deprotonations of the Schiff bases occur much as for the $\mathrm{H}^{+}$-pumping rhodopsins. In many 
cases, these deprotonations result in the proton release/uptake reactions with the external medium. Thus, the proton-transfer reactions also control the decay rates of some intermediates of photosensing rhodopsins.

The best characterized photosensing rhodopsins are SRI and SRII from archaea and bacteria. Some homologues of these SRs show the outwardly directed proton pumping activities when they exist alone in the membrane (Bogomolni et al., 1994; Sasaki \& J.L. Spudich, 2000; Sudo et al., 2001; Schmies et al., 2001). Upon the complex formations with the cognate transducers, both the proton release and uptake occur at only the extracellular side (this is so-called proton circulation) instead of the vectorial proton transport. These facts mean that SRs possess proton-transfer machinery like BR and this machinery is probably sensitive to the protein conformational change relating with the signal transduction mechanism. Like the $\mathrm{H}^{+}$-pumping rhodopsins, the states having deprotonated Schiff bases are also called Mintermediates, and are the putative signaling states for SRs. The longer lifetimes of Mintermediates are considered to increase the signaling efficiencies. Thus, the reprotonations of the Schiff bases influence the signaling efficiencies.

Studies on two SRIIs from Natronomonas pharaonis (NpSRII) (Kamo et al., 2001; J.L. Spudich \& Luecke, 2002; Pebay-Peyroula et al., 2002; Klare et al., 2004) and H. salinarum (HsSRII) (Sasaki \& J.L. Spudich, 1998, 1999) have revealed the differences in the proton-transfer reactions associated with their M-intermediate decays. For NpSRII, the reprotonation of the Schiff base occurs by uptaking a proton directly from the bulk due to the lack of a proton donor to the Schiff base (corresponding to Asp96BR). Therefore the M-decay in NpSRII is very slow as compared with $\mathrm{BR}$ and depends on the $\mathrm{pH}$ of the medium (Miyazaki et al., 1992). For HsSRII, on the other hand, there are two proton-transfer pathways in the decay of the M-intermediate. One is the pathway in which the proton comes directly from the bulk to the Schiff base, and the other is the pathway in which the proton comes from an unidentified $\mathrm{X}-\mathrm{H}$ residue. Which proton pathway becomes the major component is dependent on the $\mathrm{pH}$ of the medium (Sasaki \& J.L. Spudich, 1999; Tamogami et al., 2010). In addition, it has been reported that NpSRII possesses the $\mathrm{H}^{+}$-pumping activity (Sudo et al., 2001; Schmies et al., 2001) but HsSRII does not (Sasaki \& J.L. Spudich, 1999, 2000). Thus, despite their identical physiological functions, NpSRII and HsSRII have several differences with respect to their photocycles and proton transfers. For these photosensing rhodopsins, therefore, it would be of interest to investigate the photo-induced proton-transfer mechanisms as well as their relations with the photosignaling transductions to the cognate transducers.

\section{Importance of measurements of the photo-induced proton transfer of microbial rhodopsins}

As described above, the proton movements between the residues inside the protein as well as between the residue and the external space occur during the photocycles of most microbial rhodopsins. The protein conformational changes during the photocycles alter the $\mathrm{pKa}$ of the residues and thereby cause the proton-transfer reactions. For $\mathrm{H}^{+}$-pumping rhodopsins, these proton movements directly couple with their functional mechanisms, and for the photosensing rhodopsins, these movements affect the signal transduction efficiencies by controlling the decay rates of some intermediates and reflect the conformational alterations by the complex formation with the cognate transducers. For respective proton- 
transfer reaction, a proton moves from an amino acid residue having smaller $\mathrm{pKa}$ to one having higher $\mathrm{pKa}$. Then, if the $\mathrm{pKa}$ of the residue from which the proton is released to the external medium is larger than the $\mathrm{pH}$ in the medium, the proton cannot be released. For such a case, a subsequent proton movement (e.g., a proton uptake from the medium) occurs prior to the release. This "traffic jam" of the proton movement actually occurs in the photocycle of BR (Balashov, 2000). The pKa of its PRC at the proton-releasing state is about 6 (Zimányi et al., 1992; Balashov, 2000). Under an acidic $\mathrm{pH}$ sufficiently lower than $\mathrm{pH} \mathrm{6}$, proton uptake is observed prior to the release (see Figs. 1A and 2B). Therefore, the extent of the $\mathrm{pH}$-dependence of the proton release/uptake could be utilized to estimate the $\mathrm{pKa}$ value of a residue that is important for the proton-transfer reaction. Similarly, the proton-transfer rate may afford information about some important amino acid residues. To analyze these reactions, it is necessary to detect a small $\mathrm{pH}$ change in the external medium due to the proton movements caused during a single photocycle.

\section{Necessity of a device to measure rapid $\mathrm{pH}$ changes or proton-transfer rates at any $\mathrm{pH}$}

The photocycle of the ion-pumping rhodopsins completes in $~ 50-100 \mathrm{~ms}$, and many photosensing rhodopsins have slower photocycle of $\sim \mathrm{sec}$. A pH glass electrode is too slow to respond to such $\mathrm{pH}$ changes. For such a rapid reaction induced by a flash, the $\mathrm{pH}$ change is usually obtained using $\mathrm{pH}$-sensitive dyes whose absorbance depends on $\mathrm{pH}$ (Heberle, 2000). This is a convenient method and the rapid change is measurable. However, there is a weak point in that the medium $\mathrm{pH}$ should be restricted at $\mathrm{pH}$ near the $\mathrm{pKa}$ values of the dyes. In other words, the measurements under various medium $\mathrm{pH}$ values cannot be performed with a single dye. In addition, the subtraction of the signal in the co-presence of a dye and a rhodopsin from that of the rhodopsin alone should be performed. If one wants to estimate the $\mathrm{pKa}$ of an important amino acid residue, the $\mathrm{pH}$ profile of the magnitude and/or the rate of the proton transfer are indispensable. Hence, a device is needed for the detection of $\mathrm{pH}$ changes or proton-transfer rates at any $\mathrm{pH}$. In the following sections, we will describe an electrochemical cell using an indium-tin oxide (ITO) or tin oxide $\left(\mathrm{SnO}_{2}\right)$ electrode and its application to the microbial rhodopsins. This electrochemical cell is a useful device for these measurements due to its high sensitivity and rapid time-resolution.

\section{An ITO (or $\mathrm{SnO}_{2}$ ) electrode works as a $\mathrm{pH}$-sensitive electrode}

Koyama and his coworkers first developed this method using BR (Miyasaka \& Koyama, 1991; Miyasaka et al., 1992). They constructed a photo-electrochemical cell in which BRs were absorbed on a $\mathrm{SnO}_{2}$-coated transparent glass electrode, and detected the electric current evoked by constant illumination by using another $\mathrm{SnO}_{2}$ electrode as a reference electrode. The origin of this electric current was assumed to be the charge displacement by BR (Koyama et al., 1994). On the other hand, Robertson and Lukashev suggested that the origin of this signal is the medium $\mathrm{pH}$ change caused by the photoinduced proton release and uptake in BR (Robertson \& Lukashev, 1995). Actually, our group confirmed this suggestion by the following results of three experiments (Tamogami et al., 2009). 1) The equilibrium potential of an ITO electrode showed a linear relationship to $\mathrm{pH}$ (see Fig. 2A). 2) The amplitudes of photoelectrical signals decreased with increasing buffer concentration (see Fig. 2B). 3) HR from N. pharaonis (NpHR), an inwardly directed $\mathrm{Cl}^{-}$pump, did not cause 
a photoelectrical signal. HR is known to be converted into an $\mathrm{H}^{+}$pump in the presence of azide (Váró et al., 1996). In accordance with this, a photoelectrical signal was evoked from the HR-adsorbed electrode by the addition of azide (see Fig. 2C and Koyama et al., 1998b). Thus it was established that an ITO $\left(\right.$ or $\left.\mathrm{SnO}_{2}\right)$ electrode works as a $\mathrm{pH}$-sensitive electrode.
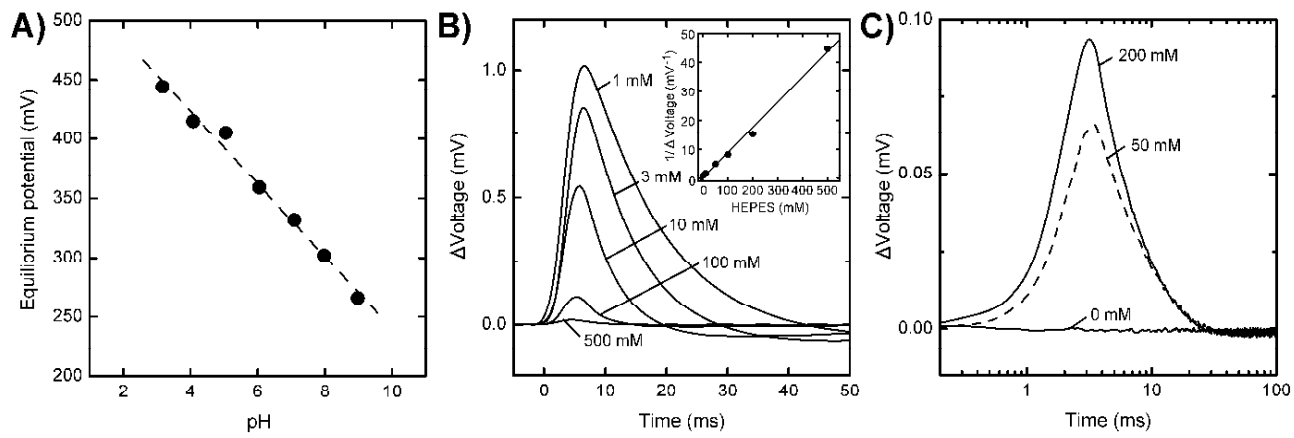

Fig. 2. An ITO (or $\left.\mathrm{SnO}_{2}\right)$ electrode works as a $\mathrm{pH}$-sensitive electrode.

A) The relationship between the equilibrium potential of ITO and $\mathrm{pH}$. B) The effect of buffer on the photo-induced signals in BR by the ITO electrode. The inset shows the plot of the reciprocal of the amplitudes of ITO signals against buffer concentrations. The experimental medium contains $400 \mathrm{mM} \mathrm{NaCl}$ and HEPES of each concentration $(1,3,10,100$ and $500 \mathrm{mM})$ at $\mathrm{pH}$ 7.5. The excitation light (2 ms duration) was $>520 \mathrm{~nm}$. C) The photo-induced ITO signals in $\mathrm{NpHR}$ in the presence and absence of azide. Experiments were performed in medium containing $133 \mathrm{mM} \mathrm{Na}_{2} \mathrm{SO}_{4}$, azide at each concentration $(0,50$ and $200 \mathrm{mM})$ and 1 $\mathrm{mM}$ HEPES at $\mathrm{pH}$ 7.0. The excitation light (2 ms duration) was $>440 \mathrm{~nm}$. NpHR was expressed in the E. coli expression system, and then was reconstituted with Egg L-aphosphatidylcholine. Other experimental setups are described in Fig. 3 and previous report (Tamogami et al., 2009). Panels A and B were adapted with permission from Tamogami et al., 2009, Photochem. Photobiol. Copyright 2009 The authors, Journal Compilation, The American Society of Photobiology.

\section{Measurements of proton release/uptake by BR with a rapid time resolution}

BR has been investigated in great detail. Thus, BR and its mutants are good references to show the relevance of our measurements using this electrochemical cell. Figure 3A shows a schemata of our electrochemical cell. This cell is essentially the same as that previously constructed by Koyama and coworkers with some modifications (Miyasaka et al., 1992). Illumination on the electrode-attached proteins induces the electrochemical potential change between the working and the counter ITO electrodes. Figure 3B indicates the flash-induced signals in BR. In this figure, the upward shift signifies the acidification of the medium near the working electrode. Thus, this shift signified the proton release from proteins to the bulk, while the downward shift signifies the proton uptake from the bulk to the protein. For BR, as described above, the sequence of the proton release and uptake can be altered depending on the external medium pH. For example, at pH 6.0 and 9.0, the proton release is followed by uptake, since the proton can be released from PRC at the early step of the photocycle (in the formation of $\mathrm{M}$ ). The subsequent uptake occurs in the decay of $\mathrm{N}$. On the other hand, at 
$\mathrm{pH}$ 3.0, the proton uptake is followed by release. This may be interpreted as meaning that the proton cannot be released from $\mathrm{PRC}$ under this $\mathrm{pH}$ condition because the medium $\mathrm{pH}$ is lower than the $\mathrm{pKa}$ of PRC in the proton-releasing state (M-intermediate). Thus, the proton uptake in the decay of $\mathrm{N}$ is observed first and the release occurs in the decay of $\mathrm{O}$ concomitantly with the deprotonation of Asp85BR (see the arrow with a broken line in Fig. 1A). The same proton-transfer sequence was also observed in the PRC-lacking mutants, as shown in Fig. 4, where the data for a mutant of E194Q/E204QBR are summarized. For these PRC-lacking mutants, the proton uptake occurred first even at the neutral $\mathrm{pH}$ (see the trace labeled with "ITO signal" in Fig. 4). For wild-type BR at pH 4.5 (see Fig. 3B), the proton uptake occurred first and then overshoot of the signal was observed at around $35 \mathrm{~ms}$. This may be interpreted as the mixture of the two populations of BR. The molecules exhibiting proton uptake first constitute the major population. Other molecules constituting a minor population exhibit proton release first. The final proton transfer corresponding to proton uptake (decay of the positive signal) caused by the minor population is slower than the proton release of the major population. Thus, the signal amplitude of this system can reflect the ratio of two kinds of molecules having different proton-transfer sequence.

In this measurement system, the time course of the photo-induced proton transfer can also be determined. Figure 4 shows the comparison of three types of signals measured for the E194Q/E204Q ${ }^{B R}$ mutant. These are (1) flash-induced absorbance changes of the mutant itself measured at three typical wavelengths; (2) a photo-induced $\mathrm{pH}$ change measured by the ITO system and; (3) the corresponding signal measured by a $\mathrm{pH}$-sensitive dye, pyranine. The sign of the pyranine signal is opposite that of ITO. For pyranine, the upward shift signifies the proton uptake, while the downward shift signifies the proton release. As shown in this figure, the proton uptake and release agree well with the formation and decay of $\mathrm{O}$, which are represented by the absorbance change at $660 \mathrm{~nm}$. This is the typical proton-transfer sequence of the PRC-disabled mutant (Brown et al., 1995; Balashov et al., 1997; Dioumaev et al., 1998, Koyama et al., 1998a). The response of the dye is very fast and completely follows the $\mathrm{pH}$ change within this time range. The time course of the dye signal almost coincides with that of ITO signal. Thus, our current ITO measurement system can monitor the $\mathrm{pH}$ change in the time range of ca. $10 \mathrm{~ms}$ to several hundred milliseconds (Tamogami et al., 2009). This could be utilized to identify the intermediate accompanying the proton-transfer reaction.
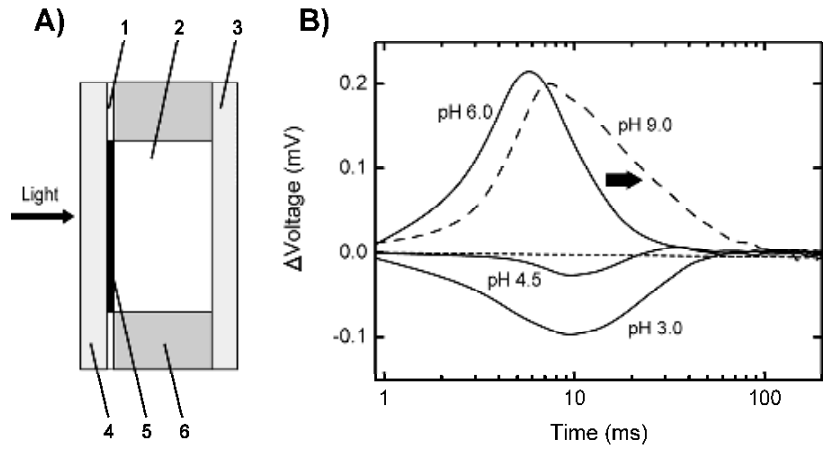

Fig. 3. The measurement of the photo-induced proton transfer in BR by the ITO transparent electrode. 
(A) The structure of the photoelectrochemical cell constructed by using ITO electrodes. (1) A silicon sheet; (2) electrolyte plus buffer; (3) a counter ITO electrode; (4) a working ITO electrode; (5) a thin layer of the sample dried on the electrode surface; (6) a Lucite chamber. The emf change between the two ITO electrodes was picked up by an AC amplifier with a low-cut filter of $0.08 \mathrm{~Hz}$ which eliminated the baseline fluctuation. This limited the duration of observation time. (B) Flash light (2 ms)-induced signals in BR under varying $\mathrm{pH}$ values. Measurements were carried out in a solution containing $400 \mathrm{mM} \mathrm{NaCl}$ and $1 \mathrm{mM}$ 6-mixed buffer (citrate/MES/MOPS/HEPES/CHES/CAPS) adjusted to the desired $\mathrm{pH}$ with $\mathrm{HCl}$ or $\mathrm{NaOH}$. BR indicates the purple membrane prepared by a standard method (Becher \& Cassim, 1975). The 6-mixed buffer was used because of its almost constant buffer capacities in a wide $\mathrm{pH}$ range. Panel B was adapted with permission from Tamogami et al., 2009, Photochem. Photobiol. Copyright 2009 The authors, Journal Compilation, The American Society of Photobiology.

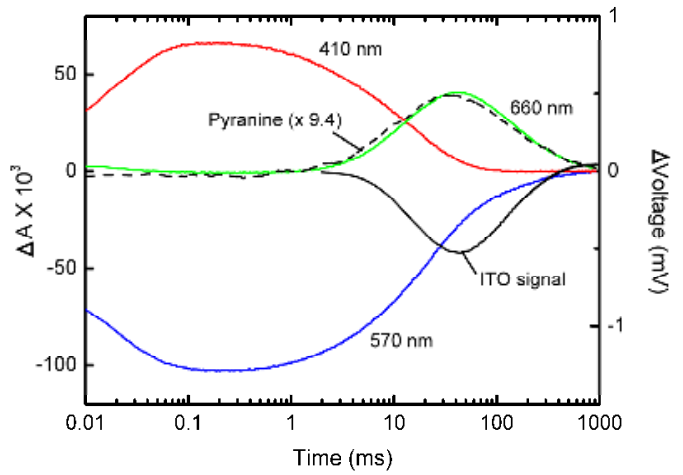

Fig. 4. Comparison between the flash-induced absorbance changes and proton-transfer signals in E194Q/E204Q ${ }^{\text {BR. }}$

The red, blue and green lines represent absorbance changes of BR at 410, 570 and $660 \mathrm{~nm}$, where the M-intermediate, unphotolyzed state and O-intermediate are mainly monitored, respectively. These traces were obtained by the flash photolysis spectroscopy performed by the procedure as described previously (Sato et al., 2003). The black broken and solid lines are the pyranine's signal (monitored at $450 \mathrm{~nm}$ ) and ITO signal, respectively. Measurements of the absorbance changes of $\mathrm{BR}$ and pyranine were performed in the solution containing $400 \mathrm{mM} \mathrm{NaCl}$ plus $0.5 \mathrm{mM}$ HEPES at pH 7.1 as described elsewhere (Tamogami et al, 2009). On the other hand, the ITO experiment was performed as shown in Fig. 3 in a solution containing $400 \mathrm{mM} \mathrm{NaCl}$ plus $1 \mathrm{mM}$ 6-mixed buffer at $\mathrm{pH}$ 7.1. The protein sample was the purple membrane isolated from $H$. salinarum expressing this mutant.

\section{Estimation of the $\mathrm{pKa}$ values of important residues involved in the photo- induced proton transfer of BR}

It is a pronounced advantage of the ITO electrode method that the measurements can be performed over a wide $\mathrm{pH}$ region. Since the buffer capacity is kept constant for the measuring $\mathrm{pH}$ range by mixing the buffering agents and the detected $\mathrm{pH}$ changes are quite small due to the very faint amount of the adsorbed protein, the measured voltage changes 
are proportional to the numbers of protons moved by the photo-induced transfer. By analyzing these voltage changes, the $\mathrm{pKa}$ values concerned with the proton transfer can be estimated as described below. Figure 5A shows the peak magnitude of the voltage changes by $\mathrm{BR}$ (peak values in Fig. 3B) measured under different medium $\mathrm{pH}$ values. As shown in this figure, below $\mathrm{pH} \sim 5$, the proton uptake was followed by the proton release. On the other hand, above $\mathrm{pH} \sim 5$, the proton release was followed by the proton uptake. Corresponding to these two $\mathrm{pH}$ ranges, the $\mathrm{pH}$ profile consists of two bell-shaped functions having opposite signs. This suggests the contribution of the four $\mathrm{pKa}$ 's of residues involved in the proton-transfer reactions. Then, this $\mathrm{pH}$ profile can be expressed by the following equation:

$$
\Delta \text { Voltage }=-A\left(\frac{1}{1+10^{p K a_{1}-p H}}\right)\left(\frac{1}{1+10^{p H-p K a_{2}}}\right)+B\left(\frac{1}{1+10^{p K a_{3}-p H}}\right)\left(\frac{1}{1+10^{p H-p K a_{4}}}\right)
$$

where $\mathrm{A}$ and $\mathrm{B}$ are constants used to adjust the magnitude of the response, and the four $\mathrm{pKa}$ values from $\mathrm{pKa} \mathrm{a}_{1}$ to $\mathrm{pKa} \mathrm{a}_{4}$ are assumed to increase in this order. A fitting analysis using Eq. 1 gave the following $\mathrm{pKa}$ values: $\mathrm{pKa}_{1}=2.6, \mathrm{pKa}_{2}=4.1, \mathrm{pKa}_{3}=6.1$ and $\mathrm{pKa} 4=9.0$. For $\mathrm{BR}$, the $\mathrm{pKa}$ values involved in the photo-induced proton transfer had been estimated mainly by various spectroscopic measurements (Balashov, 2000). The pKa's determined by the ITO method agreed well with those previously reported. Therefore, the origins of the estimated $\mathrm{pKa}$ 's were verified on the basis of previous reports. As a result, the $\mathrm{pKa}$ 's from $\mathrm{pKa} \mathrm{a}_{1}$ to $\mathrm{pKa} \mathrm{a}_{4}$ were identified as the pKa's of Asp85BR in the dark, PRC in the O-intermediate, PRC in the M-intermediate and PRC in the dark, respectively. In addition to this analysis using the peak voltages, the rates of the voltage changes were also informative. The proton uptake by Asp96 ${ }^{\mathrm{BR}}$ from the $\mathrm{CP}$ space, which coincides with $\mathrm{N}$ decay, becomes slow as the medium $\mathrm{pH}$ increases (see the traces at $\mathrm{pH} 6$ and $\mathrm{pH} 9$ in Fig. 3B). The rate constants of the proton uptake obeyed the Henderson-Hasselbalch equation with a single $\mathrm{pKa}$, and the value of Asp96BR during $\mathrm{N}$ decay was estimated at 7.8 (Tamogami et al., 2009). This value also agreed with the previously reported value (Balashov, 2000). These $\mathrm{pKa}$ values determined by the ITO method are considered those of key amino acid residues for the proton pumping function of BR. Therefore this method is useful for detecting the proton transfer directly and deducing the important $\mathrm{pKa}$ values.

\section{Application to other $\mathrm{H}^{+}$-pumping rhodopsins}

This ITO method has been successfully applied to the newly found $\mathrm{H}^{+}$-pumping rhodopsins (Tamogami et al., 2009; Kikukawa et al, 2011). The panels B and C in Fig. 5 are the results for ARII from marine algae and PR from marine bacteria, respectively. Interestingly, the $\mathrm{pH}$ profiles of these three proton pumps are quite different. The prominent differences are as follows: (1) The pH profiles of the three rhodopsins commonly have bell-shaped negative peak areas, indicating that the proton uptake occurs prior to the release. However, the negative peak of $\mathrm{PR}$ is located at a quite higher $\mathrm{pH}(\mathrm{pH} 8)$ than the other two rhodopsins ( $\mathrm{pH} 3 \sim 4$ ). This reflects the difference of the most acidic $\mathrm{pKa}$ 's, governing the $\mathrm{pH}$ where the proton uptake starts to occur. These $\mathrm{pKa}$ 's correspond to those of aspartates (Asp85BR, Asp81 $\mathrm{ARII}$ and Asp97PR), the counterions of the respective protonated Schiff bases. This $\mathrm{pKa}$ for PR is about 7, which is much higher than the pKa's of about 2.6 of the other two rhodopsins. This high $\mathrm{pKa}$ for PR reported by using spectroscopic methods (Dioumaev et 
al., 2002; Friedrich et al., 2002; Lakatos et al., 2003; Imasheva et al., 2004; Partha et al, 2005). Thus, we obtained the same result via direct measurements of the proton-transfer reactions. (2) As the $\mathrm{pH}$ increases, all three rhodopsins begin their proton releases prior to their proton uptakes.

The positive areas of the $\mathrm{pH}$ profiles correspond to this proton-transfer sequence. However, the starting $\mathrm{pH}$ 's, which reflect the $\mathrm{pKa}$ 's of the proton-releasing residues, are different. These pKa values are about 6.1 for BR, 8 for ARII and 10 for PR, respectively. The higher $\mathrm{pKa}$ 's of ARII and PR might reflect the absence of residues constituting the PRC of BR. ARII lacks a residue corresponding to Glu194BR, one of two glutamates constituting the PRC. By using the mutant of ARII, we confirmed that another glutamate, Glu199ARII, which corresponds to Glu204BR, functions as the proton-releasing residue (unpublished data). On the other hand, PR lacks both glutamates. For PR, therefore, an unknown residue works as the proton-releasing residue. (3) The $\mathrm{pH}$ profile of ARII has a surprising feature: the magnitude of the proton release again increases with a further increase in $\mathrm{pH}$ above 10. This indicates that a certain residue, other than Glu199ARI, starts to work as the proton-releasing residue at this $\mathrm{pH}$ range. These observations suggest that, despite the identical function, these proton pumps possess partially different mechanisms. Thus various interesting phenomena have been discovered by the experiments using the ITO method.

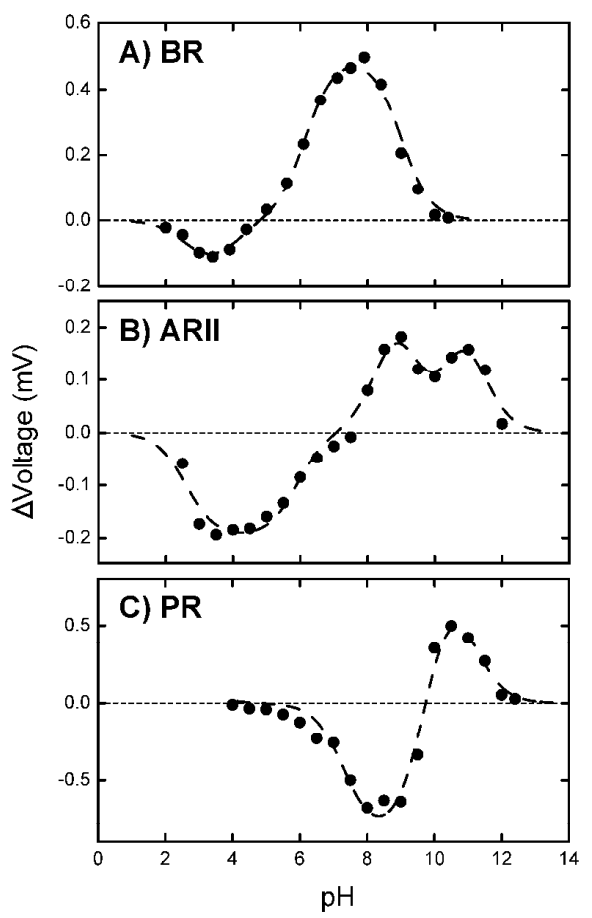

Fig. 5. Comparison of the $\mathrm{pH}$ profile of the photo-induced proton transfer among various microbial rhodopsins: (A) BR; (B) ARII; (C) PR. 
The peak values of the photo-induced signals were plotted against the medium $\mathrm{pH}$. The experimental conditions were identical to those described in Fig. 3. For BR, the purple membrane prepared by a standard method (Becher \& Cassim, 1975) was used. ARII and PR were expressed in the cell-free system and E. coli expression system, respectively, and then they were reconstituted with Egg L-a-phosphatidylcholine. Panels A and C was adapted with permission from Tamogami et al., 2009, Photochem. Photobiol. Copyright 2009 The authors, Journal Compilation, The American Society of Photobiology. Panel B was adapted with permission from Kikukawa et al., 2011, Biochemistry. Copyright 2011 American Chemical Society.

\section{Application to photosensing rhodopsins}

This ITO method is also applicable to the proton transfers of photosensing rhodopsins. We have adopted this method for the archaeal sensory rhodopsins, NpSRII (Iwamoto et al., 1999), HsSRII (Tamogami et al., 2010) and a putative new class of photosensing rhodopsin called sensory rhodopsin III from Haloarcular marismortui (HmSRIII) (Nakao et al., 2011).

Consequently, we successfully determined the timings of the proton uptake/release during their respective photocycles. These results are attributed to the high sensitivity of this method as compared with an alternative method using a $\mathrm{pH}$-sensitive dye. Most photosensing rhodopsins have slow photocycles $(\sim \sec )$. This slow turnover rate of the photocycle makes it difficult to adopt the $\mathrm{pH}$-sensitive dye method for this measurement. The absorbance change due to the $\mathrm{pH}$-sensitive dye is very small, and so a slight baseline fluctuation of the absorbance change results in a significant artifact. Especially for a longterm measurement corresponding to the slow photocycle, this baseline fluctuation becomes prominent.

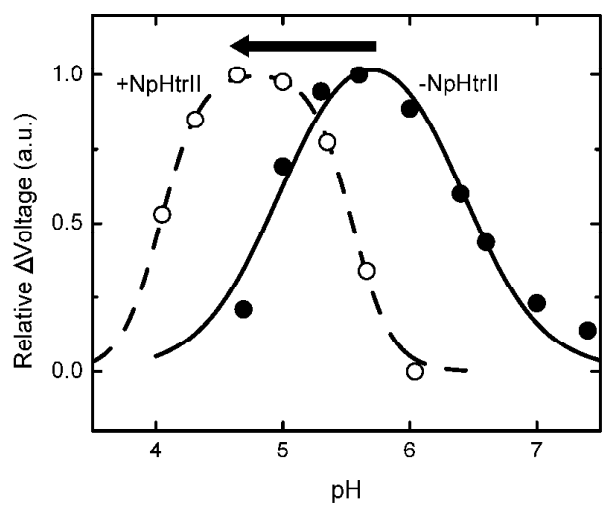

Fig. 6. The $\mathrm{pH}$ profiles of the photo-induced proton transfer in NpSRII in the presence and absence of $\mathrm{NpHtrII}_{1-159 \text {. }}$

The values of the data points at $10 \mathrm{~ms}$ after flash light (the duration of $4 \mathrm{~ms}$ ) excitation were plotted against $\mathrm{pH}$. The closed and open symbols are the plots in the absence and presence of NpHtrII $1-159$, respectively. The NpSRIIs reconstituted with L-a-phosphatidylcholine were employed for the measurements. Added NpHtrIIs were truncated from the 1st to the 159th amino acid. The other experimental conditions were identical to those described in Fig. 3. 
Adapted with permission from Iwamoto et al., 2004, Biochemistry. Copyright 2004 American Chemical Society.

For the three sensory rhodopsins examined so far, we confirmed that the rates of proton uptake reactions determined the decay of their respective M-intermediates, the putative signaling states. In addition to these, we also detected the alterations in the proton-transfer reactions of NpSRII by the complex formation with its cognate transducer, called NpHtrII (Iwamoto et al., 2004). Figure 6 shows the $\mathrm{pH}$ profile of the photo-induced proton transfer in NpSRII in the presence and absence of NpHtrII. As shown here, NpSRII releases a proton prior to the uptake at this $\mathrm{pH}$ range. From the mutation analyses, the proton-releasing residue was identified as Asp193NpSRII (corresponding to Glu204BR), which is located at the end of the EC channel. Then, the lower and higher $\mathrm{pKa}$ 's governing the bell-shaped $\mathrm{pH}$ profile were attributed to the $\mathrm{pKa}$ 's of Asp193NpSRII at the M-intermediate for release and at the dark state, respectively. As shown in this figure, the $\mathrm{pH}$ profile in the presence of $\mathrm{NpHtrII} \mathrm{shifts} \mathrm{to} \mathrm{a} \mathrm{lower} \mathrm{pH}$ compared to that in the absence of NpHtrII, implying that the complex formation induces the conformational change of NpSRII and leads to the $\mathrm{pKa}$ changes of Asp193NpSRII. In the crystal structures, the significant conformational change around Asp193 ${ }^{\mathrm{NpSRII}}$ was not observed by the complex formation (Gordeliy et al., 2002). Thus, the pKa's of the proton-transfer reactions could be responsive to a small perturbation of the conformation.

The bell-shaped $\mathrm{pH}$ profile of NpSRII, showing the first proton release, is shifted to acidic $\mathrm{pH}$ regions as compared with the positive peaks of the proton pumps shown in Fig. 5. This reflects the lower pKa's of Asp193NpSRII, the proton-releasing residue. For NpSRII, the binding of $\mathrm{Cl}^{-}$to the vicinity of Asp193NpSRII was suggested by the ITO method (Iwamoto et al., 2004), ATR-FTIR measurement (Kitade et al., 2009) and the crystal structure (Royant et al., 2001), while this $\mathrm{Cl}^{-}$binding is not known for the proton pumps examined so far. The physiological meaning of the much lower $\mathrm{pKa}$ of Asp193NpSRII should be examined in a future study.

\section{Conclusion and future perspectives}

The electrochemical cell using ITO (or $\mathrm{SnO}_{2}$ ) electrodes is a powerful and convenient device to detect the proton movements associated with photo-induced reactions of microbial rhodopsins and probably other photoactive pigments. Due to the high sensitivity and rapid response, this system enables us to follow the proton movements during a single photocycle under various buffer conditions. As described above, our current system cannot follow a reaction faster than $10 \mathrm{~ms}$. The first proton movements of microbial rhodopsins appear to occur within 0.1-1 ms. Thus, the system response should be improved. On this point, we have already confirmed that the combination of nsec laser pulse with a homemade amplifier can accelerate the response to about $20 \mu \mathrm{s}$.

Early studies on the microbial rhodopsins concerned exclusively four rhodopsins in $H$. salinarum. BR in particular attracted much interest and was investigated in great detail. Thus, BR has been considered a kind of prototype of microbial rhodopsins. However, newly found microbial rhodopsins would seem to challenge the prototype status of BR, since they possess features not seen in BR, as described above. Microbial rhodopsins have been found in a wide variety of microorganisms living in various environments. Thus, it is reasonable to 
consider that the newly found rhodopsins acquired their original mechanisms to adapt to their living environments. In this report, we showed the $\mathrm{pH}$-dependent proton movements of BR, ARII, PR and NpSRII (Figs. 5 and 6). Even though only four rhodopsins were considered, their $\mathrm{pH}$ dependences were quite different. This might reflect the mechanical divergence of microbial rhodopsins. In the future, a detailed analysis of each rhodopsin will certainly be important. This should be achieved by using various amino acid mutants. Moreover, the proton movements of many more microbial rhodopsins should be examined using this electrochemical cell. From these studies, we could obtain deeper insights into the mechanistic principles of individual rhodopsins.

\section{References}

Balashov, S.P.; Imasheva, E.S.; Ebrey, T.G.; Chen, N.; Menick, D.R. \& Crouch, R.K. (1997). Glutamate-194 to cysteine mutation inhibits fast light-induced proton release in bacteriorhodopsin. Biochemistry, Vol.36, No.29, pp. 8671-8676, ISSN 0006-2960

Balashov, S.P. (2000). Protonation reactions and their coupling in bacteriorhodopsin. Biochim. Biophys. Acta., Vol.1460, No.1, pp. 75-94, ISSN 0005-2728

Balashov, S.P.; Imasheva, E.S.; Boichenko, V.A.; Antón, J.; Wang, J.M. \& Lanyi, J.K. (2005). Xanthorhodopsin: a proton pump with a light-harvesting carotenoid antenna. Science, Vol.309, No.5743, pp. 2061-2064, ISSN 0036-8075

Becher, B. \& Cassim, J.T. (1975). Improved isolation procedures for the purple membrane of Halobacterium halobium. Prep. Biochem., Vol.5, No.2, pp. 161-178, ISSN 0032-7484

Béjà, O.; Aravind, L.; Koonin, E.V.; Suzuki, M.T.; Hadd, A.; Nguyen, L.P.; Jovanovich, S.B.; Gates, C.M.; Feldman, R.A.; Spudich, J.L.; Spudich, E.N. \& DeLong, E.F. (2000). Bacterial rhodopsin: Evidence for a new type of phototrophy in the sea. Science, Vol.289, No.5486, pp. 1902-1906, ISSN 0036-8075

Bogomolni, R.A. \& Spudich J.L. (1982). Identification of a third rhodopsin-like pigment in phototactic Halobacterium halobium. Proc. Natl. Acad. Sci. USA, Vol.79, No.20, pp. 6250-6254, ISSN 0027-8424

Bogomolni, R.A.; Stoeckenius, W.; Szundi, I.; Perozo, E.; Olson, K.D. \& Spudich, J.L. (1994). Removal of transducer HtrI allows electrogenic proton translocation by sensory rhodopsin I. Proc. Natl. Acad. Sci. USA, Vol.91, No.21, pp. 10188-10192, ISSN 00278424

Brown, L.S.; Sasaki, J.; Kandori, H.; Maeda, A.; Needleman, R. \& Lanyi, J.K. (1995). Glutamic acid 204 is the terminal proton release group at the extracellular surface of bacteriorhodopsin. J. Biol. Chem., Vol.270, No.45, pp. 27122-27126, ISSN 0021-9258

Dioumaev, A.K.; Richter, H-T.; Brown, L.S.; Tanio, M.; Tuzi, S.; Saito, H.; Kimura, Y.; Needleman, R. \& Lanyi, J.K. (1998). Existence of a proton transfer chain in bacteriorhodopsin: Participation of Glu-194 in the release of protons to the extracellular surface. Biochemistry, Vol.37, No.8, pp. 2496-2506, ISSN 0006-2960

Dioumaev, A.K.; Brown, L.S.; Shih, J.; Spudich, E.N.; Spudich, J.L. \& Lanyi, J.K. (2002). Proton transfers in the photochemical reaction cycle of proteorhodopsin. Biochemistry, Vol.41, No.17, pp. 5348-5358, ISSN 0006-2960

Essen L.O. (2002). Halorhodopsin: Light-driven ion pumping made simple? Curr. Opinion Struct. Biol., Vol.12, No.4, pp. 516-522, ISSN 0959-440X 
Friedrich, T.; Geibel, S.; Kalmbach, R.; Chizhov, I.; Ataka, K.; Heberle, J.; Engelhard, M. \& Bamberg, E. (2002). Proteorhodopsin is a light-driven proton pump with variable vectoriality. J.Mol.Biol., Vol.321, No. 5, pp. 821-838, ISSN 0022-2836

Gordeliy, V.I.; Labahn, J.; Moukhametzianov, R.; Efremov, R.; Granzin, J.; Schlesinger, R.; Büldt, G.; Savopol, T.; Scheidig, A.J.; Klare, J.P. \& Engelhard, M. (2002). Molecular basis of transmembrane signalling by sensory rhodopsin II-transducer complex. Nature, Vol.419, No.6906, pp. 484-487, ISSN 0028-0836

Haupts, U.; Tittor, J. \& Oesterhelt, D. (1999) Closing in on bacteriorhodopsin: Progress in understanding the molecule. Annu. Rev. Biophys. Biomol. Struct., Vol.28, pp. 367-399, ISSN 1056-8700

Hazemoto, N.; Kamo, N.; Terayama, Y.; Kobatake, Y. \& Tsuda, M. (1983). Photochemistry of two rhodopsinlike pigments in bacteriorhodopsin-free mutant of Halobacterium halobium. Biophys. J., Vol.44, No.1, pp. 59-64, ISSN 0006-3495

Heberle, J. (2000). Proton transfer reactions across bacteiorhodopsin and along the membrane. Biochim. Biophys. Acta., Vol.1458, No.1, pp. 135-147, ISSN 0005-2728

Imasheva, E.S.; Balashov, S.P.; Wang, J.M.; Dioumaev, A.K. \& Lanyi, J.K. (2004). Selectivity of retinal photoisomerization in proteorhodopsin is controlled by aspartic acid 227. Biochemistry, Vol.43, No.6, pp. 1648-1655, ISSN 0006-2960

Iwamoto, M.; Shimono, K.; Sumi, M.; Koyama, K. \& Kamo, N. (1999). Light-induced proton uptake and release of pharaonis phoborhodopsin detected by a photoelectrochemical cell. J. Phys. Chem.B., Vol.103, No.46, pp. 10311-10315, ISSN 1520-6106

Iwamoto, M.; Hasegawa, C.; Sudo, Y.; Shimono, K.; Araiso, T. \& Kamo, N. (2004). Proton release and uptake of pharaonis phoborhodopsin (sensory rhodopsin II) reconstituted into phospholipid. Biochemisty, Vol.43, No.11, pp. 3195-3203, ISSN 0006-2960

Jung, K.H.; Trivedi, V.D. \& Spudich, J.L. (2003). Demonstration of a sensory rhodopsin in eubacteria. Mol. Microbiol., Vol.47, No.6, pp. 1513-1522, ISSN 0950-382X

Kamo, N.; Shimono, K.; Iwamoto, M. \& Sudo Y. (2001). Photochemistry and photoinduced proton-transfer by pharaonis phoborhodopsin. Biochemistry (Moscow), Vol.66, No.11, pp. 1277-1282, ISSN 0006-2979

Kikukawa, T.; Shimono, K.; Tamogami, J.; Miyauchi, S.; Kim, S.-Y.; Kimura-Someya, T.; Shirouzu, M.; Jung, K.-H.; Yokoyama, S. \& Kamo, N. (2011). Photochemistry of Acetabularia rhodopsin II from a marine plant, Acetabularia acetabulum. Biochemistry, Vol.50, No.41, pp. 8888-8898, ISSN 0006-2960

Kitade, Y.; Furutani, Y.; Kamo, N \& Kandori, H. (2009). Proton release group of pharaonis phoborhodopsin revealed by ATR-FTIR spectroscopy. Biochemistry, Vol.48, No.7, pp. 1595-1603, ISSN 0006-2960

Kitajima-Ihara, T.; Furutani, Y.; Suzuki, D.; Ihara, K.; Kandori, H.; Homma, M. \& Sudo, Y. (2008). Salinibacter Sensory Rhodopsin Sensory rhodopsin I-like protein from a eubacterium. J. Biol. Chem., Vol.283, No.35, pp. 23533-23541, ISSN 0021-9258

Klare, J.P.; Gordeliy, V.I.; Labahn, J.; Büldt, G.; Steinhoff, H.J. \& Engelhard, M. (2004). The archaeal sensory rhodopsin II/transducer complex: a model for transmembrane signal transfer. FEBS Lett., Vol.564, No.3, pp. 219-224, ISSN 0014-5793 
Koyama, K.; Yamaguchi, N. \& Miyasaka, T. (1994). Antibody-mediated bacteriorhodopsin orientation for molecular device architectures. Science, Vol.265, No.5173, pp. 762765, ISSN 0036-8075

Koyama, K.; Miyasaka, T.; Needleman, R. \& Lanyi, J.K. (1998a). Photoelectrochemical verification of proton-releasing groups in bacteriorhodopsin. Photochem. Photobiol., Vol.68, No.3, pp. 400-406, ISSN 0031-8655

Koyama, K.; Sumi, M.; Kamo, N \& Lanyi, J.K. (1998b). Photoelectric response of halorhodopsin from Natronobacterium pharaonis. Bioelectrochem. Bioenerg., Vol.46, No.2, pp. 289-292, ISSN 0302-4598

Lakatos, M.; Lanyi, J.K.; Szakács, J. \& Váró, G. (2003). The photochemical reaction cycle of proteorhodopsin at low pH. Biophys.J., Vol.84, No.5, pp. 3252-3256, ISSN 0006-3495

Lanyi, J.K. (2004). Bacteriorhodopsin. Annu. Rev. Physiol., Vol.66, pp. 665-88, ISSN 0066-4278

Lanyi, J.K. (2006). Proton transfers in the bacteriorhodopsin photocycle. Biochim. Biophys. Acta., Vol.1757, No.8, pp. 1012-1018, ISSN 0005-2728

Lee, K.A.; Kim, S.Y.; Choi, A.R.; Kim, S.H.; Kim, S.J. \& Jung, K.-H. Expression of membrane protein and photochemical properties of two Acetabularia rhodopsins, Abstract of 14th International Conference on Retinal Proteins, P-23, Santa Cruz, August 2-6, 2010

Luecke, H.; Schobert, B.; Stagno, J.; Imasheva, E.S.; Wang, J.M.; Balashov, S.P. \& Lanyi, J.K. (2008). Crystallographic structure of xanthorhodopsin, the light-driven proton pump with a dual chromophore. Proc. Natl. Acad. Sci. USA, Vol.105, No. 43, pp. 16561-16565, ISSN 0027-8424

Marwan, W. \& Oesterhelt, D. (1987). Signal formation in the halobacterial photophobic response mediated by a four-th retinal protein (P480). J. Mol. Biol., Vol.195, No.2, pp. 333-342, ISSN 0022-2836

Matsuno-Yagi, A. \& Mukohata, Y. (1977) Two possible roles of bacteriorhodopsin; A comparative study of strains of Halobacterium halobium differing in pigmentation. Biochem. Biophys. Res. Commun., Vol.78, No.1, pp. 237-243, ISSN 0006-291X

Miranda, M.R.M.; Choi, A.R.; Shi, L.; Bezerra Jr., A.G.; Jung, K.-H. \& Brown, L.S. (2009). The photocycle and proton translocation pathway in a cyanobacterial ion-pumping rhodopsin. Biophys. J., Vol.96, No.4, pp. 1471-1481, ISSN 0006-3495

Miyasaka, T. \& Koyama, K. (1991). Photoelectrochemical behavior of purple membrane Langmuir-Blodgett films at the electrode-electrolyte interface. Chem. Lett., Vol.20, No.9, pp. 1645-1648, ISSN 0366-7022

Miyasaka, T., Koyama, K., Itoh, I. (1992). Quantum conversion and image detection by a bacteriorhodopsin-based artificial photoreceptor. Science, Vol.255, No.5042, pp. 342344, ISSN 0036-8075

Miyazaki, M.; Hirayama, J.; Hayakawa, M. \& Kamo, N. (1992). Flash photolysis study on pharaonis phoborhodopsin from a haloalkaliphilic bacterium (Natronobacterium pharaonis). Biochim. Biophys. Acta., Vol.1140, pp. 22-29, ISSN 0005-2728

Mukohata Y., Ihara K., Tamura T. \& Sugiyama Y. (1999). Halobacterial rhodopsins. J. Biochem., Vol.125, No.4, pp. 649-657, ISSN 0021-924X

Nagel, G.; Ollig, D.; Fuhrmann, M.; Mustl, A.M.; Bamberg, E. \& Hegemann, P. (2002). Channelrhodopsin-1: a light-gated proton channel in green algae. Science, Vol.296, No.5577, pp. 2395-2398, ISSN 0036-8075

Nakao, Y.; Kikukawa, T.; Shimono, K.; Tamogami, J.; Kimitsuki, N.; Nara, T.; Unno, M.; Ihara, K. \& Kamo, N. (2011). Photochemistry of a putative new class of sensory 
rhodopsin (SRIII) coded by xop2 of Haloarcular marismortui. J. Photochem. Photobiol. B., Vol.102, No.1, pp. 45-54, ISSN 1011-1344

Oesterhelt, D. \& Stoecknius, W. (1971). Rhodopsin-like protein from the purple membrane of Halobacterium halobium. Nat. New. Biol., Vol.233, No.39, pp. 149-152, ISSN 00900028

Partha, R.; Krebs, R.; Caterino, T.L. \& Braiman, M.S. (2005). Weakened coupling of conserved arginine to the proteorhodopsin chromophore and its counterion implies structural differences from bacteriorhodopsin. Biochim. Biophys. Acta., Vol.1708, No.1, pp. 6-12, ISSN 0005-2728

Pebay-Peyroula, E.; Royant, A.; Landau, E.M.; Navarro, J. (2002). Structural basis for sensory rhodopsin function. Biochim. Biophys. Acta., Vol.1565, No.2, pp. 196- 205, ISSN 00052728

Robertson, B. \& Lukashev, E.P. (1995). Rapid pH change due to bacteriorhodopsin measured with a tin-oxide electrode. Biophys. J., Vol.68, No.4, pp. 1507-1517, ISSN 0006-3495

Royant, A.; Nollert, P.; Edman, K.; Neutze, R.; Landau, E.M.; Pebay-Peyroula, E. \& Navarro, J. (2001). X-ray structure of sensory rhodopsin II at 2.1- $\AA$ resolution. Proc. Natl. Acad. Sci. USA, Vol.98, No.18, pp. 10131-10136, ISSN 0027-8424

Sasaki, J. \& Spudich, J.L. (1998). The transducer protein HtrII modulates the lifetimes of sensory rhodopsin II photointermediates. Biophys. J., Vol.75, No.5, pp. 2435-2440, ISSN 0006-3495

Sasaki, J. \& Spudich, J.L. (1999). Proton circulation during the photocycle of sensory rhodopsin II. Biophys. J., Vol.77, No.4, pp. 2145-2152, ISSN 0006-3495

Sasaki, J. \& Spudich, J.L. (2000). Proton transport by sensory rhodopsins and its modulation by transducer-binding. Biochim. Biophys. Acta., Vol.1460, No.1, pp. 230-239, ISSN 0005-2728

Sato, M.; Kikukawa, T.; Araiso, T.; Okita, H.; Shimono, K.; Kamo, N., Demura, M. \& Nitta, K. (2003). Role of Ser130 and Thr126 in chloride binding and photocycle of pharaonis halorhodopsin. J. Biochem., Vol.134, No.1, pp. 151-158, ISSN 0021-924X

Schmies, G.; Engelhard, M.; Wood, P.G.; Nagel, G. \& Bamberg, E. (2001). Electrophysiological characterization of specific interactions between bacterial sensory rhodopsins and their transducers. Proc. Natl. Acad. Sci. USA, Vol.98, No.4, pp. 1555-1559, ISSN 0027-8424

Schobert, B. \& Lanyi, J.K. (1982). Halorhodopsin is a light-driven chloride pump. J. Biol. Chem., Vol.257, No.17, pp. 306-313, ISSN 0021-9258

Sineshchekov, O.A.; Jung, K.-H. \& Spudich, J.L. (2002). Two rhodopsins mediate phototaxis to low- and high-intensity light in Chlamydomonas reinhardtii. Proc. Natl. Acad. Sci. USA, Vol.99, No.13, pp. 8689-8694, ISSN 0027-8424

Spudich, E.N.; Sundberg, S.A.; Manor D. \& Spudich J.L. (1986). Properties of a second sensory receptor protein in Halobacterium halobium phototaxis. Proteins, Vol.1, No.3, pp. 239-246, ISSN 0887-3585

Spudich, J.L. \& Bogomolni, R.A. (1984). Mechanism of color discrimination by a bacterial sensory rhodopsin. Nature, Vol.312, No.5994, pp. 509-513, ISSN 0028-0836

Spudich, J.L.; Yang, C.-S.; Jung K.-H. \& Spudich, E.N. (2000). Retinylidene proteins: Structures and functions from archaea to humans. Annu. Rev. Cell Dev. Biol., Vol.16, pp. 365-392, ISSN 1081-0706 
Spudich, J.L. \& Luecke, H. (2002). Sensory rhodopsin II: functional insights from structure. Curr Opin Struct Biol., Vol.12, No.4, pp. 540-546, ISSN 0959-440X

Spudich, J.L, \& Jung, K.-H. (2005). Microbial rhodopsin: Phylogenetic and functional diversity, In: Handbook of photosensory receptors, Briggs, W. R. \& Spudich, J.L., Ed., pp. 1-23, Wiley-VCH Verlag, ISBN 3-527-31019-3, Weinheim

Sudo, Y.; Iwamoto, M.; Shimono, K.; Sumi, M. \& Kamo, N. (2001). Photo-induced proton transport of pharaonis phoborhodopsin (sensory rhodopsin II) is ceased by association with the transducer. Biophys. J., Vol.80, No.2, pp. 916-922, ISSN 00063495

Suzuki, T.; Yamasaki, K.; Fujita, S.; Oda, K.; Iseki, M.; Yoshida, K.; Watanabe, M.; Daiyasu, H.; Toh, H.; Asamizu, E.; Tabata, S.; Miura, K.; Fukuzawa, H.; Nakamura, S. \& Takahashia, T. (2003). Archaeal-type rhodopsins in Chlamydomonas: Model structure and intracellular localization. Biochem. Biophys. Res. Commun., Vol.301, No.3, pp. 711-717, ISSN 0006-291X

Takahashi, T.; Tomioka, H.; Kamo, N. \& Kobatake, Y. (1985). A photosystem other than P370 also mediates the negative phototaxis of Halobacterium halobium. FEMS Microbiol. Lett., Vol.28, pp. 161-164, ISSN 0378-1097

Tamogami, J.; Kikukawa, T.; Miyauchi, S.; Muneyuki, E. \& Kamo, N. (2009). A tin oxide transparent electrode provides the means for rapid time-resolved $\mathrm{pH}$ measurements: Application to photoinduced proton transfer of bacteriorhodopsin and proteorhodopsin. Photochem. Photobiol., Vol.85, No.2, pp. 578-589, ISSN 00318655

Tamogami, J.; Kikukawa, T.; Ikeda, Y.; Takemura, A.; Demura, M. \& Kamo, N. (2010). The photochemical reaction cycle and photoinduced proton transfer of sensory rhodopsin II (phoborhodopsin) from Halobacterium salinarum. Biophys. J., Vol.98, No.7, pp. 1353-1363, ISSN 0006-3495

Tomioka, H.; Takahashi, T.; Kamo, N. \& Kobatake, Y. (1986). Flash spectrophotometric identification of a fourth rhodopsin-like pigment in halobacterium halobium. Biochem. Biophys. Res. Commun., Vol.139, pp. 389-395, ISSN 0006-291X

Tsunoda, S.P.; Ewers, D.; Gazzarrini, S.; Moroni, A.; Gradmann, D. \& Hegeman, P. (2006). $\mathrm{H}^{+}$-pumping rhodopsin from the marine alga Acetabularia. Biophys. J., Vol.91, No.4, pp. 1471-1479, ISSN 0006-3495

Váró, G.; Brown, L.S.; Needleman, R. \& Lanyi, J.K. (1996). Proton transport by halorhodopsin. Biochemistry, Vol.35, No.21, pp. 6604-6611, ISSN 0006-2960

Váró, G. (2000). Analogies between halorhodopsin and bacteriorhodopsin. Biochim. Biophys. Acta., Vol.1460, No.1, pp. 220-229, ISSN 0005-2728

Váró, G.; Brown, L.S.; Lakatos, M. \& Lanyi, J.K. (2003). Characterization of the photochemical reaction cycle of proteorhodopsin. Biophys. J., Vol.84, No.2, pp. 12021207, ISSN 0006-3495

Wada T.; Shimono, K.; Kikukawa, T.; Hato, M.; Shinya, N.; Kim, S. Y.; Kimura-Someya, T.; Shirouzu, M.; Tamogami, J.; Miyauchi, S.; Jung, K.-H.; Kamo, N. \& Yokoyama, S. (2011). Crystal structure of the eukaryotic light-driven proton pumping rhodopsin, Acetabularia rhodopsin II, from marine alga. J. Mol. Biol., Vol.411, No.5, pp. 986-998, ISSN 0022-2836

Wang, J.-P.; Song, L.; Yoo, S.-K. \& El-Sayed, M.A. (1997). A comparison of the photoelectric current responses resulting from the proton pumping process of bacteriorhodopsin 
under pulsed and CW laser excitations. J. Phys. Chem.B, Vol.101, No.49, pp. 1059910604, ISSN 1520-6106

Waschuk, S.A.; Bezerra, A.G.; Shi, Jr.L. \& Brown, L.S. (2005). Leptosphaeria rhodopsin: Bacteriorhodopsin-like proton pump from a eukaryote. Proc. Natl. Acad. Sci. USA, Vol.102, No. 19, pp. 6879-6883, ISSN 0027-8424

Wolff, E.K.; Bogomolni, R.A.; Scherrer P.; Hess B. \& Stoeckenius W. (1986). Color discrimination in halobacteria: Spectroscopic characterization of a second sensory receptor covering the blue-green region of the spectrum. Proc. Natl. Acad. Sci. USA, Vol.83, No.19, pp. 7272-7276, ISSN 0027-8424

Wu, J.; Ma, D.; Wang, Y.; Ming, M.; Balashov, S.P. \& Ding, J. (2009). Efficient approach to determine the $\mathrm{pKa}$ of the proton release complex in the photocycle of retinal proteins. J. Phys. Chem.B, Vol.113, No.13, pp. 4482-4491, ISSN 1520-6106

Zimányi, L.; Váró, G.; Chang, M.; Ni, B.; Needleman, R. \& Lanyi, J.K. (1992). Pathways of proton release in the bacteriorhodopsin photocycle. Biochemistry, Vol.31, No.36, pp. 8535-8543, ISSN 0006-2960 


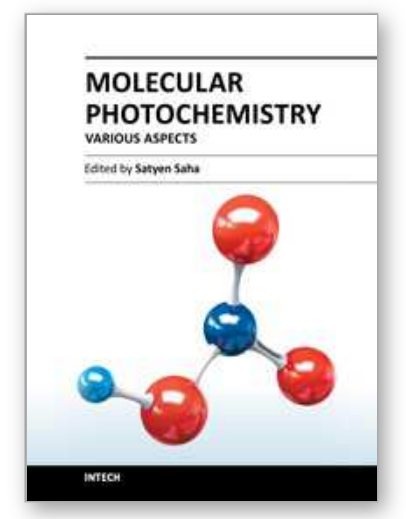

\author{
Molecular Photochemistry - Various Aspects \\ Edited by Dr. Satyen Saha
}

ISBN 978-953-51-0446-9

Hard cover, 282 pages

Publisher InTech

Published online 30, March, 2012

Published in print edition March, 2012

There have been various comprehensive and stand-alone text books on the introduction to Molecular Photochemistry which provide crystal clear concepts on fundamental issues. This book entitled "Molecular Photochemistry - Various Aspects" presents various advanced topics that inherently utilizes those core concepts/techniques to various advanced fields of photochemistry and are generally not available. The purpose of publication of this book is actually an effort to bring many such important topics clubbed together. The goal of this book is to familiarize both research scholars and post graduate students with recent advancement in various fields related to Photochemistry. The book is broadly divided in five parts: the photochemistry I) in solution, II) of metal oxides, III) in biology, IV) the computational aspects and V) applications. Each part provides unique aspect of photochemistry. These exciting chapters clearly indicate that the future of photochemistry like in any other burgeoning field is more exciting than the past.

\title{
How to reference
}

In order to correctly reference this scholarly work, feel free to copy and paste the following:

Takashi Kikukawa, Jun Tamogami, Kazumi Shimono, Makoto Demura, Toshifumi Nara and Naoki Kamo (2012). Photo-induced Proton Transfers of Microbial Rhodopsins, Molecular Photochemistry - Various Aspects, Dr. Satyen Saha (Ed.), ISBN: 978-953-51-0446-9, InTech, Available from:

http://www.intechopen.com/books/molecular-photochemistry-various-aspects/photo-induced-proton-transfersof-microbial-rhodopsins

\section{INTECH}

open science | open minds

\section{InTech Europe}

University Campus STeP Ri

Slavka Krautzeka 83/A

51000 Rijeka, Croatia

Phone: +385 (51) 770447

Fax: +385 (51) 686166

www.intechopen.com

\section{InTech China}

Unit 405, Office Block, Hotel Equatorial Shanghai

No.65, Yan An Road (West), Shanghai, 200040, China

中国上海市延安西路 65 号上海国际贵都大饭店办公楼 405 单元

Phone: +86-21-62489820

Fax: $+86-21-62489821$ 
(C) 2012 The Author(s). Licensee IntechOpen. This is an open access article distributed under the terms of the Creative Commons Attribution 3.0 License, which permits unrestricted use, distribution, and reproduction in any medium, provided the original work is properly cited. 